\title{
Role of limonin in anticancer effects of Evodia rutaecarpa on ovarian cancer cells
}

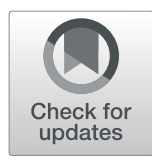

Jae Ryul Bae, Wook Ha Park, Dong Hoon Suh, Jae Hong No, Yong Beom Kim and Kidong Kim

\begin{abstract}
Background: Ovarian cancer therapy generally involves systemic chemotherapy with anticancer drugs; however, chemotherapy with a platinum-based drug has often been shown to cause adverse reactions and drug resistance in ovarian cancer patients. Evodia rutaecarpa (ER) reportedly shows anticancer activity against various types of cancer cells. However, the effects of ER have not yet been fully uncovered in ovarian cancer.

Methods: In the present study, we investigated the anticancer effects of an ER extract and its components against the ovarian cancer cell lines SKOV-33, A2780, RMUG-S and a cisplatin-resistant SKOV-3 cell line (Cis ${ }^{R}$ SKOV-3). Cell viability and colony formation assays along with subcellular fractionation analysis, immunoblotting, and immunofluorescence staining were performed.
\end{abstract}

Results: ER treatment led to a significant reduction in the viability of SKOV-3 cells. Moreover, limonin, a compound found in ER, reduced the viability of both serous-type (SKOV-3 and A2780) and mucinous-type (RMUG-S) ovarian cancer cells by inducing apoptosis via activation of the p53 signaling pathway. Furthermore, limonin reversed the drug resistance through activation of apoptosis in $\mathrm{Cis}^{\mathrm{R}}$ SKOV-3.

Conclusion: Taken together, our findings suggest that limonin contributes to the anti-ovarian cancer effects of ER by inducing apoptosis via activation of the p53 signaling pathway.

Keywords: Evodia rutaecarpa, Limonin, p53, Apoptosis, Cisplatin resistance

\section{Background}

Globally, ovarian cancer is the 7th most common cancer and the 8th leading cause of cancer mortality in women [1]. The initial treatment for ovarian cancer involves surgery, followed by chemotherapy. Despite the high response rate to first-line chemotherapeutic drugs, recurrence of ovarian cancer occurs in many cases. Moreover, in patients with ovarian cancer, chemotherapy with existing anticancer drugs, such as cisplatin, leads to adverse reactions and the development of chemoresistance. Adverse reactions, together with chemoresistance, contribute to the failure of anticancer therapy. To address these problems, development of drugs using natural products has been on the rise,

\footnotetext{
* Correspondence: kidong.kim.md@gmail.com

Department of Obstetrics and Gynecology, Seoul National University Bundang Hospital, Seongnam, Republic of Korea
}

as these compounds are considered novel candidate therapeutic agents to treat several types of cancer, with multiple therapeutic effects and few side effects [2,3].

Evodia rutaecarpa (ER), an oriental medicine, has traditionally been used for the treatment of headaches, gastrointestinal diseases, amenorrhea, and postpartum hemorrhage [4-6]. An analytical study on the chemical composition of ER has reported that the plant contains alkaloids, carboxylic acids, essential oils, flavonoids, and limonoids [7]. Several studies have reported that ER and its derivatives exhibit multiple biological activities, including anti-inflammatory, anti-obesity, antihypertensive, and anti-allergic effects [8-10]. Recently, two studies have reported that the activation of caspases and AMPactivated protein kinase by an ethanol extract of ER led to apoptosis of cervical cancer cells and benign prostatic hyperplasia epithelial cells, respectively $[11,12]$. The

(C) The Author(s). 2020 Open Access This article is licensed under a Creative Commons Attribution 4.0 International License, which permits use, sharing, adaptation, distribution and reproduction in any medium or format, as long as you give appropriate credit to the original author(s) and the source, provide a link to the Creative Commons licence, and indicate if changes were made. The images or other third party material in this article are included in the article's Creative Commons licence, unless indicated otherwise in a credit line to the material. If material is not included in the article's Creative Commons licence and your intended use is not permitted by statutory regulation or exceeds the permitted use, you will need to obtain permission directly from the copyright holder. To view a copy of this licence, visit http://creativecommons.org/licenses/by/4.0/ The Creative Commons Public Domain Dedication waiver (http://creativecommons.org/publicdomain/zero/1.0/) applies to the data made available in this article, unless otherwise stated in a credit line to the data. 
finding that the ER extract inhibits proliferation in various cell lines indicates that the plant or its components may have anticancer activity.

Limonin, one of the compounds found in ER [13, 14], is the major limonoid and a bitter compound, mainly found in seeds. Several studies have indicated that limonin shows biological activities, including antioxidant, antiinflammatory, and antiviral effects [15-17]. Validation studies have demonstrated the anticancer effects of limonin in various cancer cell lines [18-23]. Mechanistic investigations have shown that limonin inhibits cell growth by inducing apoptosis. For example, both hepatoma HepG2 and colon cancer SW480 cells were shown to exhibit increased levels of proapoptotic proteins, including Bax and caspase-3, with limonin treatment [18, 19]. Moreover, limonin exhibited cytotoxicity toward a human breast cancer cell line, MCF-7, via activation of caspase-7, without disrupting the activity of aromatase [20]. Thus, numerous studies have shown that limonin exerts common anticancer effects against various cancer cell lines, suggesting that it has a therapeutic potential for treating various cancers. However, there is limited evidence regarding the antiovarian cancer effects of ER and limonin.

Hence, in this study, we explored the pharmacological potential of ER against ovarian cancer and the role of limonin in the anticancer effects of ER.

\section{Methods}

\section{Cell culture and reagents}

SKOV-3 and A2780, human ovarian cancer cell lines of serous histology, and RMUG-S, a human ovarian cancer cell line of mucinous histology, were obtained from the American Type Culture Collection (Rockville, MD, USA) and the Japanese Collection of Research Bioresources Cell Bank (Osaka, Japan), respectively. The serous-type cell lines, SKOV-3 and A2780, were cultured in Roswell Park Memorial Institute 1640 medium (Welgene, Kyungsan, Republic of Korea) containing 10\% fetal bovine serum and 1\% penicillin-streptomycin (Invitrogen, Carlsbad, CA, USA), and the mucinous-type cell line, RMUG-S, was cultured in DMEM/F12 (Sigma-Aldrich, St. Louis, MO, USA) containing 10\% fetal bovine serum and $1 \%$ penicillin-streptomycin in a humidified incubator at $37^{\circ} \mathrm{C}$ with $5 \% \mathrm{CO}_{2}$.

A water extract of ER was obtained from the National Development Institute of Korean Medicine (Kyungsan, Republic of Korea), and synephrine and limonin were purchased from ChemFaces (Wuhan, China). DMSO (Sigma-Aldrich) was used to dissolve the ER extract, synephrine, and limonin.

\section{Generation of a cisplatin-resistant $\left(\mathrm{Cis}^{\mathrm{R}}\right)$ cell line}

To generate $\mathrm{Cis}^{\mathrm{R}}$ cells, we followed previously reported methods [24], with slight modifications. Briefly, the $\mathrm{IC}_{50}$ value of cisplatin (Sigma-Aldrich) against the SKOV-3 cell line was determined by incubating cells with cisplatin $(0.01-100 \mathrm{mM})$ for $72 \mathrm{~h}$ and plotting a concentrationresponse curve. The determined $\mathrm{IC}_{50}$ value of cisplatin was used in subsequent experiments. After $72 \mathrm{~h}$, the medium was changed to a fresh medium, without cisplatin, to recover the cells, and then the $\mathrm{Cis}^{\mathrm{R}}$ subline was continuously maintained for 6 months, according to the developmental protocol. After the developmental period, a new $\mathrm{IC}_{50}$ value was determined in a concentrationresponse experiment with cisplatin, and $\mathrm{Cis}^{\mathrm{R}}$ cells were maintained with a concentration of cisplatin equal to the new $\mathrm{IC}_{50}$ for a further 6 months.

\section{Cell viability assay}

The cell viability assay was performed using the PrestoBlue $^{\mathrm{mx}}$ reagent (Invitrogen), according to the manufacturer's manual. Serous or mucinous ovarian cancer cells were seeded into a 96-well plate (1000 cells per well in growth media) and cultured to approximately $60-70 \%$ confluence. The ER extract, synephrine, and limonin, with and without pifithrin- $\alpha$ (PFT- $\alpha$; Selleckchem, Houston, TX, USA), were added to the seeded cells, and the cells were incubated for 24, 48, and $72 \mathrm{~h}$. Subsequently, a diluted PrestoBlue reagent was added to each well, and the plate was incubated for $2 \mathrm{~h}$ in a humidified incubator at $37^{\circ} \mathrm{C}$ with $5 \% \mathrm{CO}_{2}$. Afterward, absorbance was measured at $540 \mathrm{~nm}$ using a microplate reader.

\section{Colorimetric caspase- 3 assay}

The caspase- 3 activity assay was performed using a caspase-3/CPP32 colorimetric assay kit (BioVision, Milpitas, CA, USA) according to the manufacturer's recommended protocols. Briefly, ER-, synephrine-, and limonintreated cells were lysed in a cell lysis buffer. Subsequently, the protein concentrations were determined in the lysates using a BCA assay (Thermo Fisher Scientific, Waltham, MA, USA) according to the manufacturer's instructions. The protein samples $(150-200 \mu \mathrm{g})$ were mixed with $2 \times$ reaction buffer containing $10 \mathrm{mM}$ DTT and incubated at $37^{\circ} \mathrm{C}$ for $2 \mathrm{~h}$, followed by the addition of the DEVD-pNA substrate $(200 \mu \mathrm{M})$. After the reaction, caspase-3 activity was measured by reading the absorbance at $400 \mathrm{~nm}$ using a microplate reader.

\section{Colony formation assay}

To perform the colony formation assay, we followed previously reported methods [25] with slight modifications. SKOV-3 cells were plated (500 cells) in a $60-\mathrm{mm}$ culture dish and cultured for 2 weeks. Thereafter, the cells were treated with the ER extract for $72 \mathrm{~h}$ and then fixed with $4 \%$ PFA. After fixation, the cells were stained with a solution containing $0.5 \%$ crystal violet (Sigma-Aldrich) in $25 \%$ methanol for $2 \mathrm{~h}$, then washed, and observed. 


\section{Subcellular fractionation and immunoblotting}

Nuclear and cytosolic proteins were separately extracted from cells using a nuclear/cytosol fractionation kit (BioVision) according to the manufacturer's manual. For immunoblotting, cells were treated with synephrine or limonin, with and without PFT- $\alpha$, and then lysed in a lysis buffer containing $50 \mathrm{mM}$ Tris- $\mathrm{HCl}$ (pH 7.5), $0.5 \%$ Triton X-100, $150 \mathrm{mM} \mathrm{NaCl}, 0.5 \mathrm{mM}$ EGTA, and a protease inhibitor mixture (Roche, Basel, Switzerland). Protein concentrations in the cell lysates were determined using the BCA assay, and the proteins $(20-30 \mu \mathrm{g})$ were mixed with an SDS sample buffer. The samples were boiled at $90{ }^{\circ} \mathrm{C}$ for $10 \mathrm{~min}$ and then separated by electrophoresis in $10-15 \%$ polyacrylamide gels. The separated proteins were transferred onto polyvinylidene difluoride membranes, which were blocked by incubation in TBST buffer with $5 \%$ nonfat milk or $5 \%$ bovine serum albumin (BSA) for $1 \mathrm{~h}$. Afterward, the membranes were incubated with the following primary antibodies: p53 (1:1000; Abcam, Cambridge, UK), p65 (1:1000; Abcam), Bcl-2 (1: 1000; Abcam), $\alpha$-tubulin (1:5000; Cell Signaling Technology, Danvers, MA, USA), histone H3 (1:1000; Cell Signaling Technology), Bax (1:1000; Cell Signaling Technology), survivin (1:1000; Cell Signaling Technology), cleaved caspase-3 (1:1000; Cell Signaling Technology), and cleaved PARP1 (1:1000; Cell Signaling Technology) at $4{ }^{\circ} \mathrm{C}$ overnight. Next, the membranes were washed with TBST buffer, then incubated with horseradish peroxidase-conjugated secondary antibodies (1:5000; Cell Signaling Technology) at room temperature for $1 \mathrm{~h}$, and washed again. Immunoreactive bands were detected using an enhanced chemiluminescence solution (Millipore, Burlington, MA, USA) in the dark.

\section{Immunofluorescence and imaging}

For immunofluorescence microscopy, SKOV-3 cells were plated on coverslips, then treated with DMSO and limonin for $24 \mathrm{~h}$, and fixed with $4 \%$ paraformaldehyde. The fixed cells were permeabilized with $0.2 \%$ Triton X-100, and the coverslips were blocked with $5 \%$ BSA. Afterward, the cells were incubated with primary antibodies against p53 (1:50; Abcam) and p65 (1:100; Abcam) for $1 \mathrm{~h}$ and washed with PBS, followed by incubation with Alexa 488-conjugated secondary antibodies. Subsequently, the coverslips were mounted on slides using a mounting solution containing DAPI, and the stained samples were imaged using a fluorescence microscope. Z-stack and live-cell images were acquired using a laser scanning confocal microscope (Zeiss 710 Meta; Zeiss, Oberkochen, Germany) and an optical microscope (CKX53; Olympus, Tokyo, Japan), respectively.

\section{Statistical analysis}

The colony formation assay, colorimetric caspase-3 activity assay, cell viability assay, and immunoblotting data were obtained from at least three independent experiments. The colony formation assay and immunoblotting data were analyzed using ImageJ (http://rsb.info.nih.gov/ ij), and all analyzed data were graphed using Origin Pro 8.0. For statistical analysis of differences between two groups, Student's $t$-test was applied. The data are presented as the mean \pm standard error of the mean (SEM). $P<0.05$ was considered statistically significant.

\section{Results}

ER extract exerted anticancer effects in SKOV-3 cells

We found that ER treatment reduced cell density and increased membrane blebbing in SKOV-3 cells (Fig. 1a). Membrane blebbing has been shown to indicate apoptosis [26]. To investigate the effect of the ER extract in ovarian cancer cells, the viability of ER-treated SKOV-3 cells was assessed and found to be significantly reduced in a concentration- and time-dependent manner (Fig. 1b). To examine whether the reduced viability of ER-treated cells was due to apoptosis, we measured caspase-3 activity. Compared with that in the control, ER-treated cells showed a significant increase in caspase-3 activation, in a concentration- and time-dependent manner (Fig. 1c). To further examine whether cell proliferation was inhibited by ER treatment, we performed a colony formation assay under the treatment conditions used for SKOV-3 cells, as discriminative cell viability and caspase- 3 activity were observed under particular treatment conditions (for example, $100 \mu \mathrm{g}$ of ER extract for $72 \mathrm{~h}$ ). As expected, the number of colonies was significantly reduced by ER treatment compared with that in the control (Fig. 1d and e). Collectively, these results suggested that the ER extract exerted an anticancer effect via activation of caspase-3-dependent apoptosis in ovarian cancer cells.

\section{Limonin but not synephrine reduced the viability of SKOV-3, A2780, and RMUG-S cells}

To determine the compound that contributed to the inhibitory effect of the ER extract in the ovarian cancer cell line, SKOV-3, we selected two ER-derived compounds, namely, synephrine and limonin (Fig. 2a), and assessed their effects on the viability of the SKOV-3, A2780, and RMUG-S ovarian cancer cell lines. Limonin-exposed cells showed a significant reduction in their viability in a concentration- and time-dependent manner; however, synephrine exhibited no effect (Fig. 2c-e). In addition, the $\mathrm{IC}_{50}$ values of limonin indicated that the mucinous ovarian cancer cell line, RMUG-S, was more susceptible to limonin than were the ovarian cancer cell lines of the serous-type at an early time point (Fig. 2b). Taken together, these results indicated that limonin inhibited the viability of the mucinous-type as well as the serous-type ovarian cancer cell lines, implying that the anticancer effect of the ER extract was due to limonin. 


\section{a}

ER treat $(100 \mu \mathrm{g} / \mathrm{mL})$

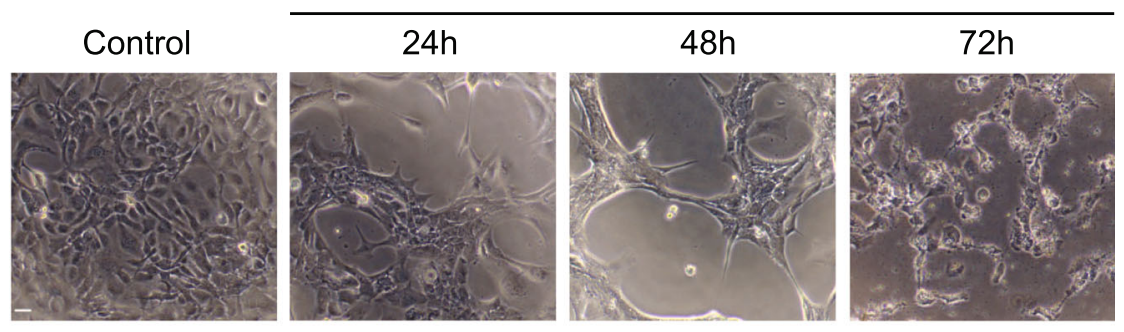

b

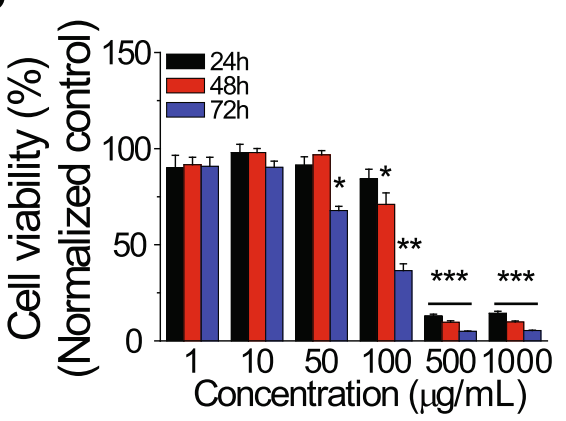

C

d

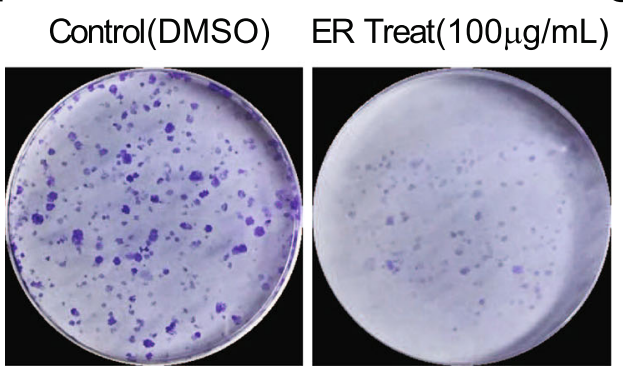

e

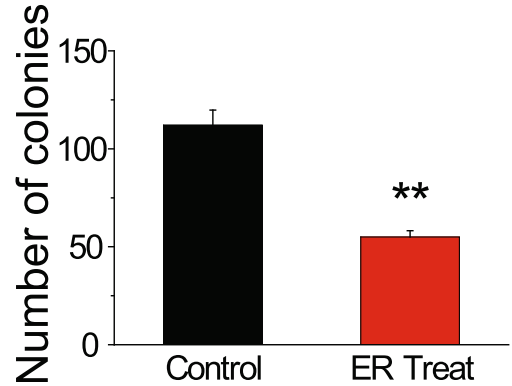

Fig. 1 Effects of the Evodia rutaecarpa (ER) extract on viability of and caspase-3 activity in SKOV-3 ovarian cancer cells. (a) Representative images of cells treated with the control (DMSO) and the ER extract $(100 \mu \mathrm{g} / \mathrm{mL}$ ) for 24,48 , and $72 \mathrm{~h}$. Scale bar $=10 \mu \mathrm{m}$. (b) Viability of and (c) caspase-3 activity in cells treated with the ER extract (1, 10,50, 100, 500, and $1000 \mu \mathrm{g} / \mathrm{mL}$ ) for 24, 48, and $72 \mathrm{~h}$ (mean \pm SEM). (d) Representative images of colonies formed by control (DMSO)- and ER $(100 \mu \mathrm{g} / \mathrm{mL})$-treated cells after $72 \mathrm{~h}$ of incubation. (e) Numbers of colonies (mean \pm SEM). ${ }^{*} P<0.05$, ${ }^{* *} P<0.01,{ }^{* * *} P<0.001$

Limonin changed the subcellular localization and level of the p53 protein

We further investigated whether limonin-induced cell death was due to caspase-3-dependent apoptosis of SKOV-3 cells. Based on the results of the cell viability assay, a concentration of $10 \mu \mathrm{M}$ and an exposure time of $24 \mathrm{~h}$ were selected for the treatment with limonin. Limonin-treated cells exhibited a significantly enhanced caspase-3 activation compared with that in the control; as expected, synephrine-treated SKOV-3 cells did not exhibit any changes in the caspase- 3 activity (Fig. 3a). p53 and p65 have been reported to be key molecules regulating the induction of apoptosis in human cancers $[27,28]$. Thus, we examined whether the levels of p65 and p53 were affected by the treatment with limonin. The results of immunoblotting showed that the p53 level was significantly higher in limonin-treated SKOV-3 cells than in the control, whereas that of p65 was not different from its level in the control. Neither p53 nor p65 levels were affected by synephrine treatment (Fig. 3b-d).

Increased protein levels and nuclear p53 translocation have been implicated in the activation of p53 [29]. Therefore, we further investigated whether subcellular localization of p53 was affected by the treatment of SKOV-3 cells with different concentrations of limonin for $24 \mathrm{~h}$. Subcellular localization of the p65 protein showed no change compared with that in the control; however, the p53 protein showed enhanced translocation from the cytosol to the nuclear fraction in 
a

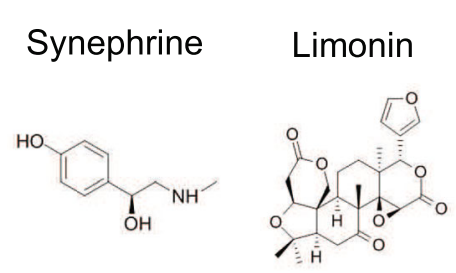

b

\begin{tabular}{cccc}
\hline \multirow{2}{*}{ Cell lines } & \multicolumn{3}{c}{ Limoinin $\mathrm{IC}_{50}(\mu \mathrm{M})$} \\
\cline { 2 - 4 } & $24 \mathrm{~h}$ & $48 \mathrm{~h}$ & $72 \mathrm{~h}$ \\
\hline SKOV-3 & $13.27 \pm 1.01$ & $6.17 \pm 0.21$ & $3.57 \pm 0.20$ \\
A2780 & $13.32 \pm 1.05$ & $6.72 \pm 0.69$ & $4.35 \pm 0.17$ \\
RMUG-S & $8.27 \pm 2.48$ & $7.04 \pm 0.26$ & $4.92 \pm 0.55$ \\
\hline
\end{tabular}

$48 h$ $72 \mathrm{~h}$
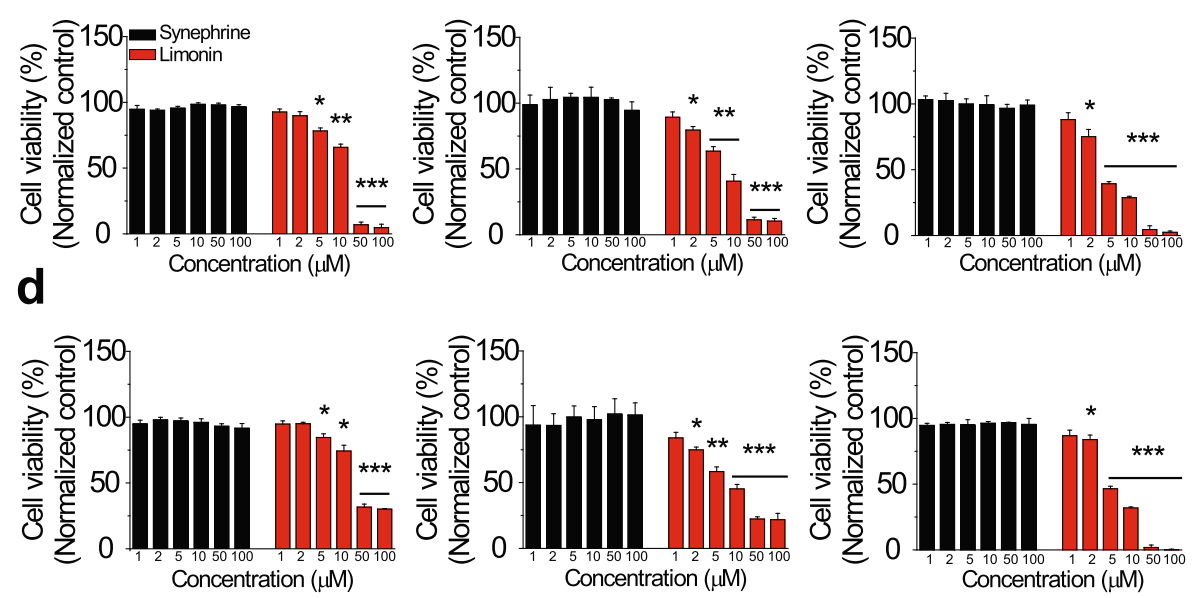

e
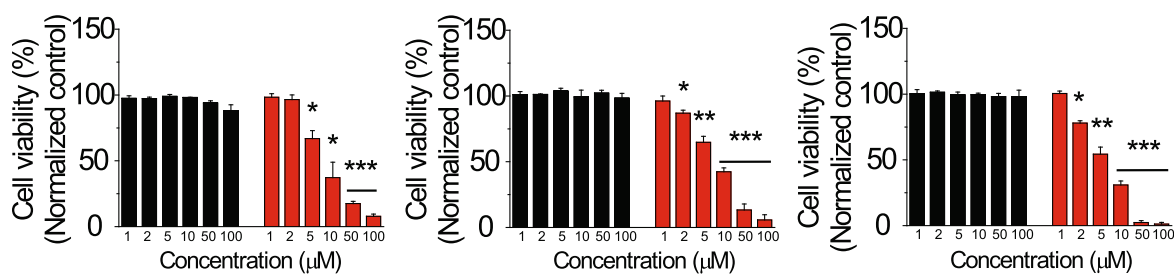

Fig. 2 Effects of limonin and synephrine on various ovarian cancer cells. (a) Chemical structures of synephrine (left) and limonin (right). (b) $I_{50}$ values of limonin against ovarian cancer cell lines, A2780, SKOV-3, and RMUG-S. (c-e) Viability of human ovarian cancer cell lines, A2780 (c), SKOV3 (d), and RMUG-S (e), treated with synephrine and limonin $(1,2,5,10,50$, and $100 \mu \mathrm{M})$ for 24,48 , and $72 \mathrm{~h}$ (mean \pm SEM). ${ }^{*} P<0.05$, ${ }^{*} P<0.01,{ }^{* * *} P<0.001$

SKOV-3 cells following limonin treatment (Fig. 4a). To confirm the localization of p53 in the nucleus, fixed cells were stained with labeled p65 and p53 antibodies following limonin treatment. A confocal Z-stack analysis revealed that signals from the stained $\mathrm{p} 53$ protein were merged with those of DAPI, indicating that the limonin treatment induced the translocation of the p53 protein to the nucleus, whereas the p65 protein was only localized to the cytosolic fraction of SKOV-3 cells (Fig. 4b and c). Taken together, these results indicated that limonin activated the p53 protein, increasing its level of expression and nuclear translocation.

\section{Limonin predominantly induced apoptosis of ovarian cancer cells via activation of $p 53$}

We performed immunoblotting to detect proteins involved in p53-mediated apoptosis pathway. Consistent with the previous results, limonin concentrationdependently increased the p53 protein level (Fig. 5a and b). Proapoptotic proteins, Bax, cleaved caspase-3, and PARP1, progressively increased in SKOV-3 cells treated with increasing concentrations of limonin (Fig. 5a, c, g, and $\mathrm{h}$ ). On the contrary, the levels of antiapoptotic proteins, Bcl-2 and survivin, concentration-dependently decreased in limonin-treated cells (Fig. 5a, d, and e).

Previous studies have reported that functionally active p53 is implicated not only in the induction of apoptosis but also in cell-cycle arrest [28, 30, 31]. Thus, we next examined whether activation of p53 by limonin would also lead to cell-cycle arrest in ovarian cancer cells. The results showed that limonin treatment non-significantly elevated the level of the p21 protein (Fig. 5a and f), suggesting that activation of 


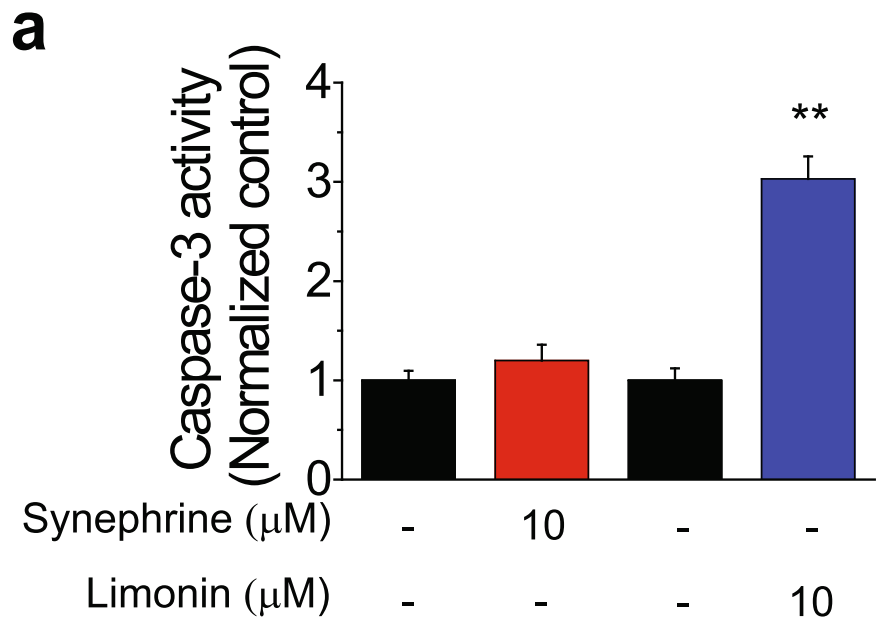

b
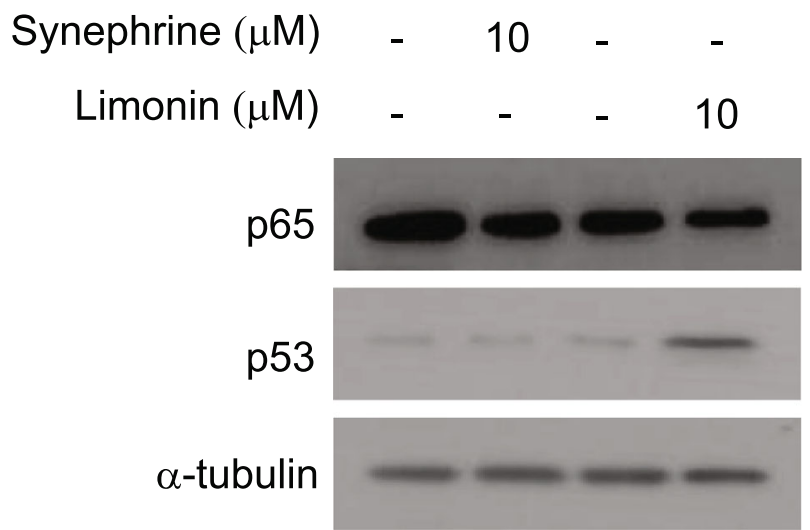

C

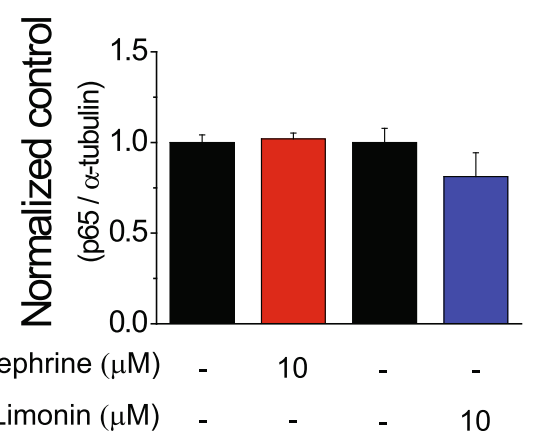

d

Fig. 3 Molecular pathways involved in the induction of apoptosis by limonin. (a) Caspase-3 activity (mean \pm SEM) in SKOV-3 cells treated with synephrine and limonin for $24 \mathrm{~h}$. (b) Immunoblotting analysis of expression levels of p53 and p65 proteins in SKOV-3 cells treated with synephrine $(10 \mu \mathrm{M})$, limonin $(10 \mu \mathrm{M})$, or DMSO (control) for $24 \mathrm{~h}$. (c, d) Quantification of p65 (c) and p53 (d) levels (mean \pm SEM) in (b). a-Tubulin was used as a loading control. ${ }^{*} P<0.05$

p53 by limonin predominantly affected the apoptotic pathway in SKOV-3 cells.

To examine whether the activation of the p53-mediated apoptosis pathway by limonin would be inhibited by a $\mathrm{p} 53$ inhibitor, we treated SKOV-3 cells with limonin in the presence or absence of the p53 inhibitor PFT- $\alpha$. The results showed that the increased levels of the proapoptotic proteins and the decreased levels of the antiapoptotic 


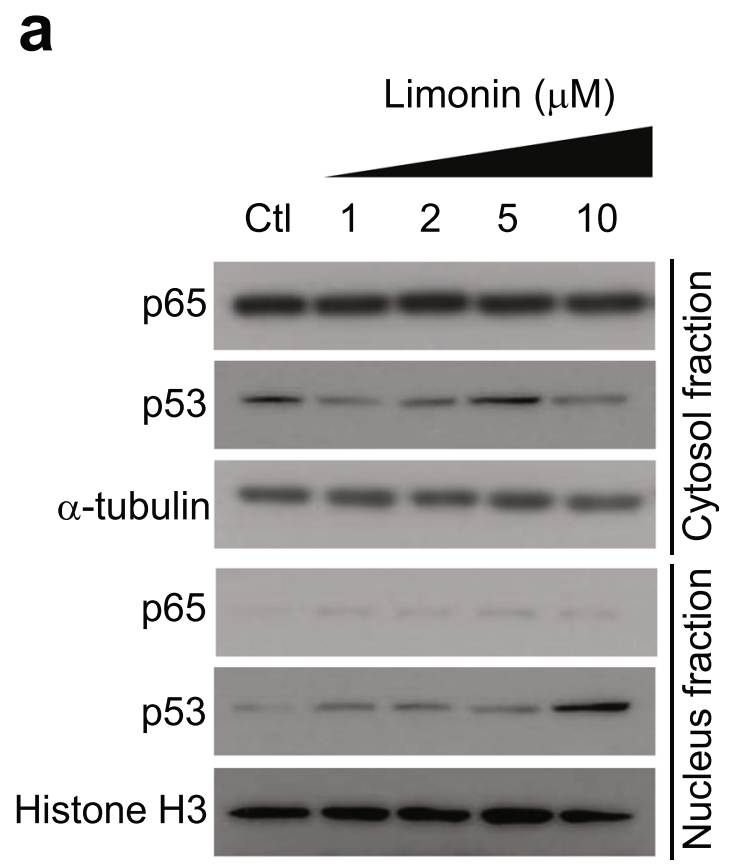

b

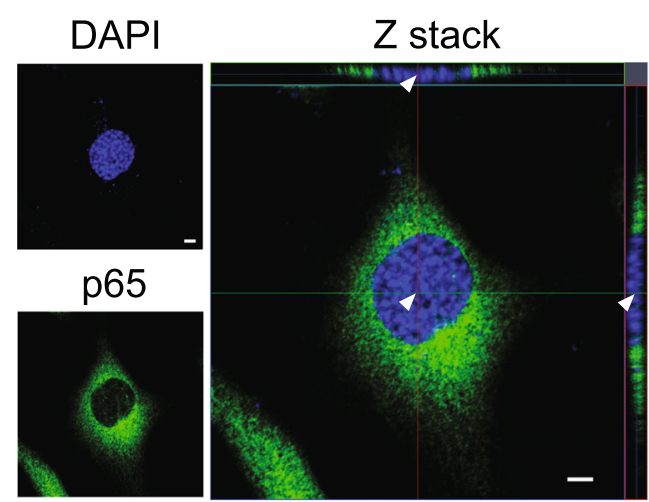

C

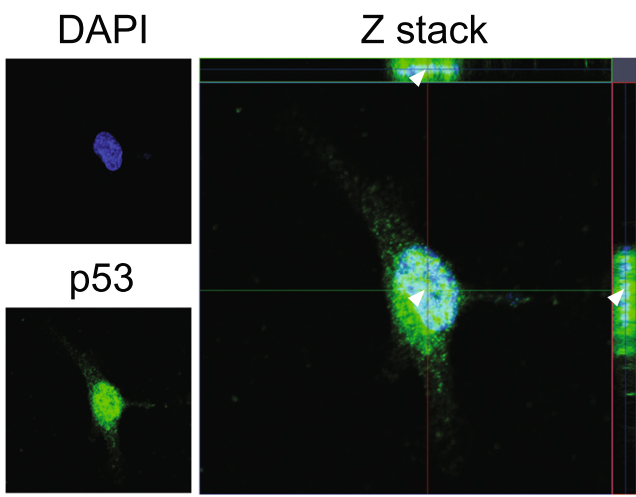

Fig. 4 Effects of limonin on subcellular localization of the p53 protein. (a) Immunoblotting analysis of p65 and p53 protein levels in subcellular fractions of cells treated with increasing concentrations of limonin or with DMSO (control). a-Tubulin and histone $\mathrm{H} 3$ were used as loading controls for the cytosol and nuclear fractions, respectively. (b, c) Z-stack images of subcellular localization of p65 (b) and p53 (c) in SKOV-3 cells. Scale bar $=5 \mu \mathrm{m}$. The arrowheads indicate nuclear localization

proteins were brought to their basal levels by the inhibition of the p53 activity (Fig. 6a-g). These findings demonstrated that activation of the p53 protein by limonin predominantly led to apoptotic cell death via the caspasedependent pathway, rather than via cell-cycle arrest in ovarian cancer cells.

\section{Reversal of cisplatin resistance in ovarian cancer cells by limonin}

Chemoresistance has often been observed in ovarian cancer patients undergoing chemotherapy with platinumbased drugs [32]. Research on the development of new molecular targeted drugs has played an important role in overcoming resistance to platinum-based drugs. Indeed, a study has shown that the natural compound cryptotanshinone reversed resistance to cisplatin in lung cancer cells [33]. We next examined whether limonin could reverse cisplatin resistance of ovarian cancer cells. To this end, we generated a $\mathrm{Cis}^{\mathrm{R}}$ ovarian cancer cell line via continuous exposure of normal SKOV-3 cells to cisplatin and evaluated the cisplatin sensitivity of the normal and $\mathrm{Cis}^{\mathrm{R}}$ cell lines. The $\mathrm{IC}_{50}$ value of cisplatin for $\mathrm{Cis}^{\mathrm{R}} \mathrm{SKOV}-3$ cells was 3.4-fold higher than that for normal SKOV-3 cells, confirming the cisplatin-resistant phenotype of the $\mathrm{Cis}^{\mathrm{R}}$ SKOV-3 cell line (Fig. 7a and b).

Subsequently, we performed a cell viability assay to explore whether limonin could reverse the resistance of ovarian cancer cells to cisplatin. The results showed a significant, concentration-dependent reduction in the viability of limonin-treated $\mathrm{Cis}^{\mathrm{R}}$ cells (Fig. 7c). To determine whether the reduction of $\mathrm{Cis}^{\mathrm{R}}$ cell viability by the treatment with limonin was also due to apoptosis via activation of the p53-mediated pathway, $\mathrm{Cis}^{\mathrm{R}}$ cells were treated with different concentrations of limonin, with and without PFT- $\alpha$, for $24 \mathrm{~h}$, and then the caspase- 3 activity assay and immunoblotting were performed. Caspase- 3 activity increased in limonin-treated $\mathrm{Cis}^{\mathrm{R}}$ cells in a concentrationdependent manner; however, the increase was reversed by inhibition of p53 activity (Fig. 7d).

Consistent with the previous results, immunoblotting indicated that limonin concentration-dependently induced the activation of p53, increased the levels of proapoptotic proteins, and decreased those of antiapoptotic proteins. Furthermore, the activation of p53-mediated apoptosis by limonin was inhibited by the treatment of 


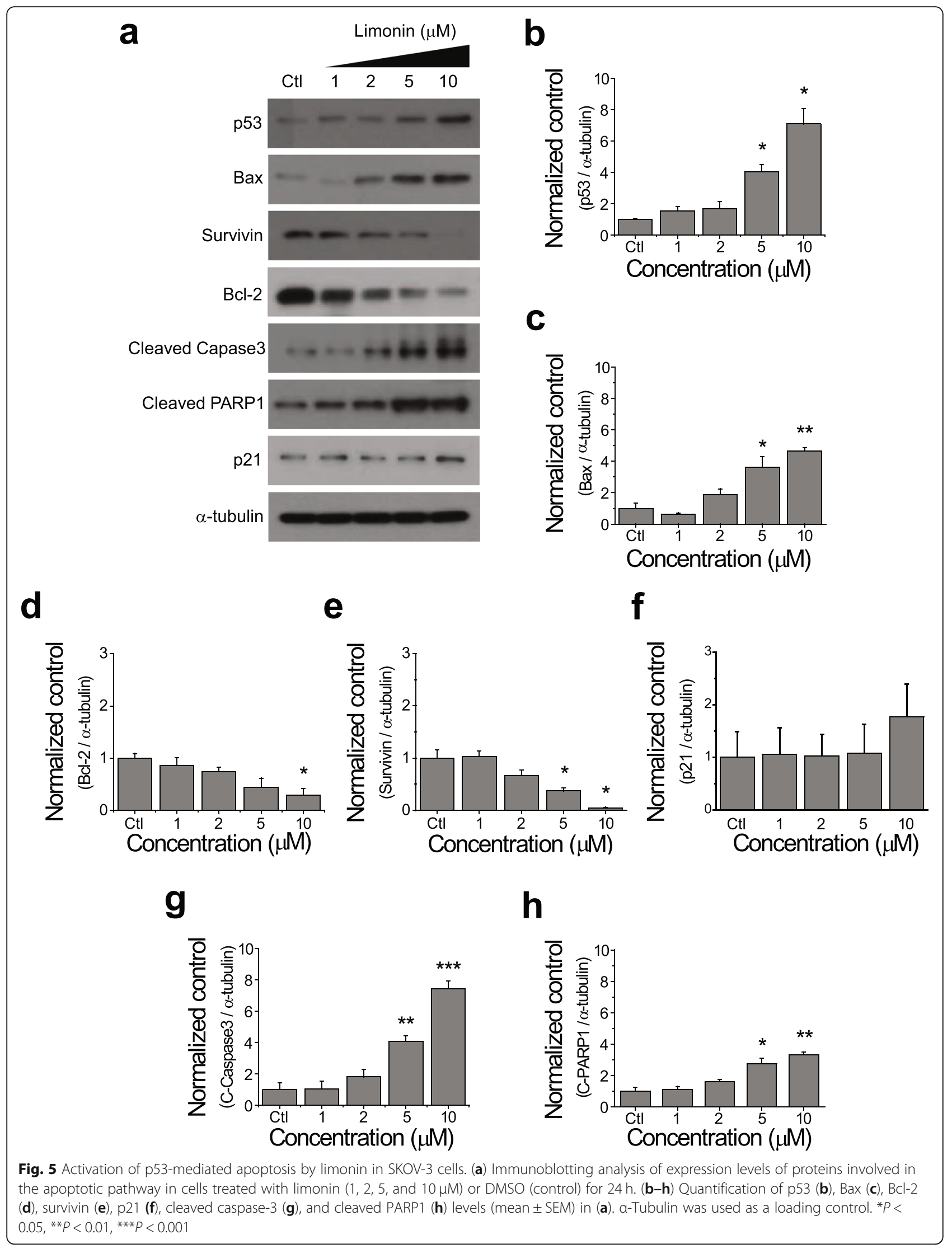




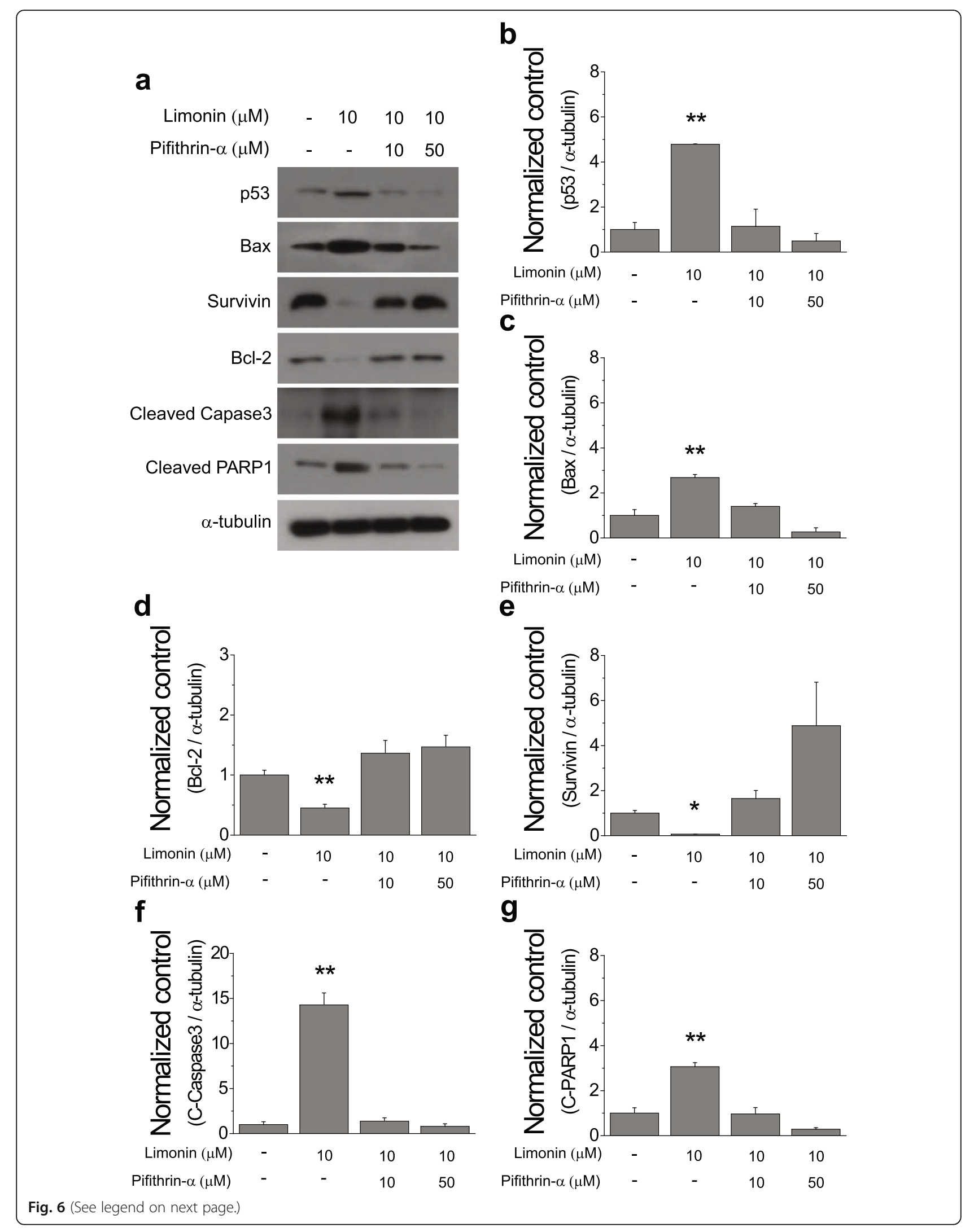


(See figure on previous page.)

Fig. 6 Effects of the p53 inhibitor PFT-a on limonin-induced apoptosis in the SKOV-3 ovarian cancer cell line. (a) Immunoblotting analysis of expression levels of proteins involved in the apoptotic pathway in cells treated with limonin alone $(10 \mu \mathrm{M})$, limonin plus PFT-a $(10$ and $50 \mu \mathrm{M})$, and DMSO (control) for $24 \mathrm{~h}$. (b-g) Quantification of p53 (b), Bax (c), Bcl-2 (d), survivin (e), cleaved caspase-3 (f), and cleaved PARP1 (g) levels (mean \pm SEM) in (a). a-Tubulin was used as a loading control. ${ }^{*} P<0.05,{ }^{* *} P<0.01$

$\mathrm{Cis}^{\mathrm{R}}$ cells with the p53 inhibitor (Fig. 7e). Collectively, these results indicated that limonin reversed the resistance of $\mathrm{Cis}^{\mathrm{R}}$ ovarian cancer cells to cisplatin via the activation of the p53-mediated apoptosis pathway.

\section{Discussion}

Natural products and their derivatives are gaining interest as novel therapeutic agents to treat several types of cancer because these substances can exert multiple anticancer effects and are associated with few side effects, unlike existing anticancer drugs. Among medicinal plants, ER has been reported in various studies to show anticancer effects [11, 12]. Several studies on ER derivatives have already shown that evodiamine has an anticancer effect in ovarian cancer cells [34, 35]. We selected limonin and synephrine as novel therapeutic candidates, potentially contributing to the effect of ER, because these a

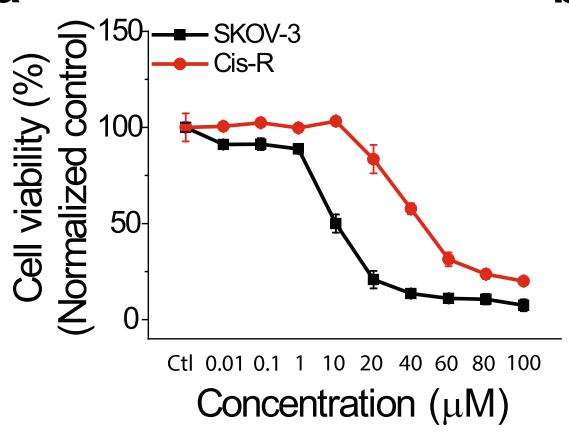

C
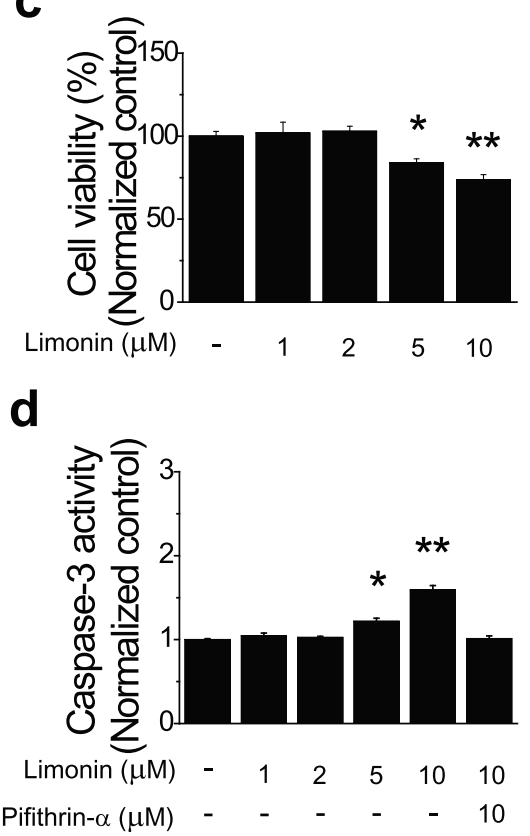

b

\begin{tabular}{cc}
\hline \multicolumn{2}{c}{ Cisplatin $\mathrm{IC}_{50}(\mu \mathrm{M})$} \\
\hline Normal SKOV-3 & $9.99 \pm 0.74$ \\
Cis-R SKOV-3 & $34.11 \pm 3.18$ \\
\hline
\end{tabular}

e
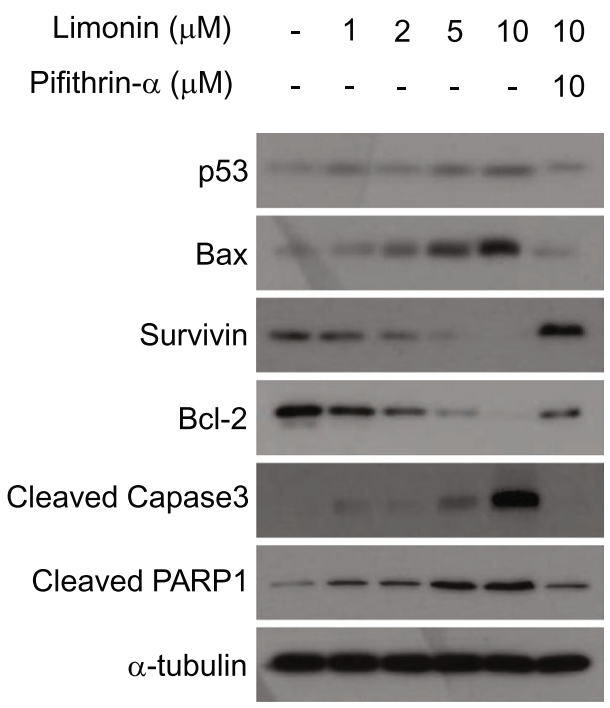

Fig. 7 Effects of limonin on cisplatin resistance of ovarian cancer cells. (a) Viability of normal and cisplatin-resistant (Cis ${ }^{R}$ ) SKOV-3 cells treated with cisplatin $(0.01-100 \mathrm{mM})$ for $72 \mathrm{~h}$. (b) $I C_{50}$ values of cisplatin against $\mathrm{Cis}^{\mathrm{R}}$ and age-matched parental SKOV-3 cells. (c) Viability of Cis ${ }^{R}$ cells treated with limonin $(1,2,5$, and $10 \mu \mathrm{M})$. (d) Caspase-3 activity and (e) immunoblotting analysis of expression levels of proteins involved in the apoptotic pathway in Cis ${ }^{R}$ SKOV-3 cells exposed to limonin $(1,2,5$, and $10 \mu \mathrm{M})$ alone, limonin plus PTF-a $(10 \mu \mathrm{M})$, or DMSO (control) for $24 \mathrm{~h}$. a-Tubulin was used as a loading control. Data are expressed as the mean \pm SEM. ${ }^{*} P<0.05,{ }^{* *} P<0.01$ 
compounds have not yet been investigated against ovarian cancer.

Our results indicated that limonin but not synephrine specifically inhibited the growth of ovarian cancer cells (Fig. 2). Further, limonin exerted its effects by enhancing caspase- 3 activity in ovarian cancer cells, indicating the induction of apoptosis. The process of apoptosis is tightly regulated through pathways related to two major molecules, p53 and p65 proteins, in human cancers. We investigated the effect of limonin on the cellular levels of p53 and p65 proteins in ovarian cancer cells and found that the limonin-induced apoptotic cell death was initiated by the activation of the p53 protein, subsequently leading to an increase in the level of p53 as well as to its nuclear translocation, thereby resulting in the activation of proteins involved in the process of apoptosis (Figs. 3 and 4).

Accumulating evidence suggests an anticancer effect of limonin via p53-mediated apoptosis. A study has shown that limonin upregulated the mRNA and protein levels of p53 in a hepatoma cell line, HepG2 [23]. Moreover, apoptotic cell death via upregulation of proapoptotic proteins and downregulation of antiapoptotic proteins by limonin treatment was commonly observed in pancreatic, breast, colon, and liver cancer cell lines [18-22]. These results are consistent with our findings, indicating that limonin exerted anticancer effects via activation of the p53-mediated apoptosis pathway in ovarian cancer cells (Fig. 8).

In our study, the mucinous-type ovarian cancer cell line RMUG-S was found to be more susceptible to limonin than were the serous types, SKOV-3 and A2780, at an early time point (Fig. 2). Several studies have provided evidence for clear differences in protein expression between serous and mucinous cell types in ovarian cancer [36-38]. For example, it has been shown that mucinous cell types are more likely to express Ecadherin than serous cell types are [37]. In addition, increased expression levels of MMPs, including MMP-2, MMP-7, and MMP-9, as well as TIMPs, including TIMP-1 and TIMP-2, were observed in mucinous ovarian cancer compared with those in serous ovarian cancer [38]. In particular, increased activity of MMP-2 and decreased expression of E-cadherin were associated with tumor growth and development $[39,40]$. The activity of MMP-2 and the expression of E-cadherin have been reported to be modulated by p53 [41, 42]. In addition, a previous study has reported that the rates of p53 mutations in the serous and mucinous types of ovarian cancer were 56 and $17 \%$, respectively [43], indicating a significantly higher p53 mutation rate in the serous-type than in the mucinous-type ovarian cancer. In this respect, we suggest that the activation of p53 by limonin in ovarian cancer cells may have affected the susceptibility of the mucinous ovarian cancer cell line via an unknown mechanism, related to the difference in protein expression between the ovarian cancer cell types. Further, the mucinous-type often exhibits resistance to platinumbased drugs during chemotherapy in the advanced stage [44]. Our results indicated that limonin reversed the resistance to cisplatin in ovarian cancer cells via activation of p53-mediated apoptosis (Fig. 7), suggesting that limonin may potentially be a novel strategic drug for chemotherapy of mucinous-type ovarian cancer.

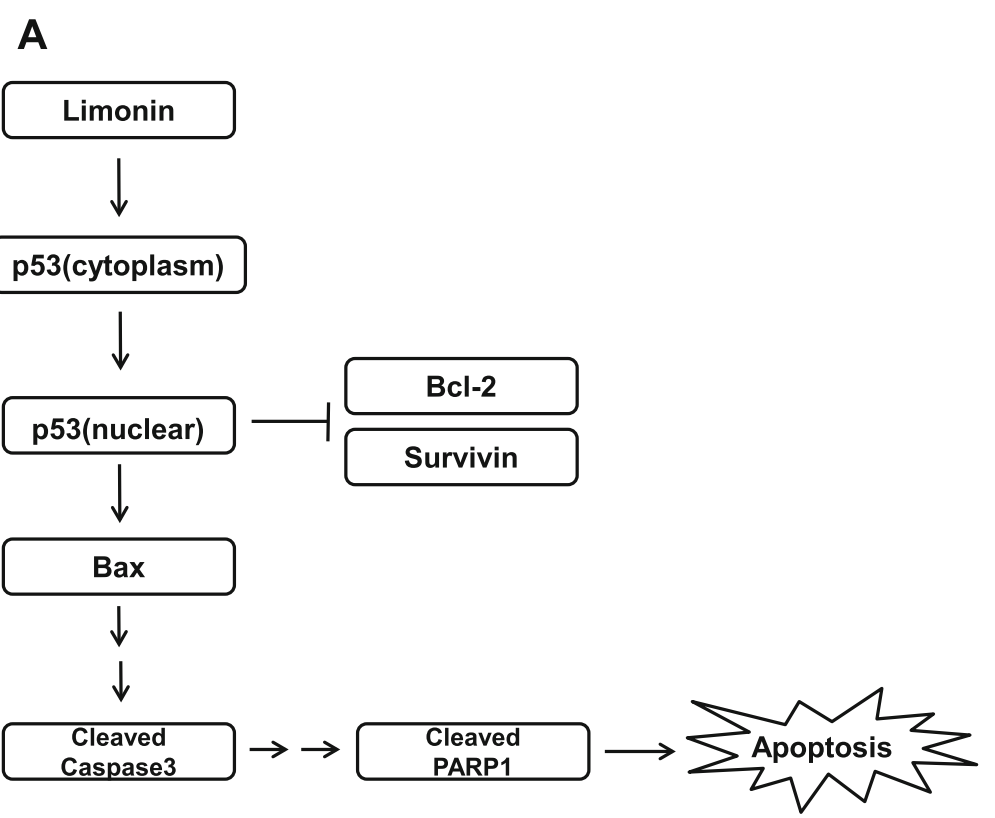

Fig. 8 Mechanism of anticancer effects of limonin in ovarian cancer 
We did not measure the content of limonin in the ER extract because we focused on the mechanism of the anticancer effect of ER and limonin. However, a previous study has reported that the content of limonin in ER was no less than $0.50 \%$ [14].

\section{Conclusions}

In conclusion, we demonstrated that limonin contributed to the anticancer effect of ER via activation of p53mediated apoptosis in ovarian cancer cells. Furthermore, we showed that limonin affected both serous and mucinous types of ovarian cancer and reversed the resistance of ovarian cancer cells to cisplatin. Limonin could be an attractive therapeutic agent for ovarian cancer.

\section{Abbreviations}

BSA: Bovine serum albumin; $\mathrm{Cis}^{\mathrm{R}}$ : Cisplatin-resistant; ER: Evodia rutaecarpa: PFT-a: Pifithrin-a; SEM: Standard error of the mean

\section{Acknowledgments}

None.

\section{Authors' contributions}

JRB and KK designed the project and wrote the manuscript. WHP performed the experiments. DHS, JHN, and YBK contributed to the discussion of the data and provided comments on the project. The authors read and approved the final manuscript.

\section{Funding}

This work was supported by a grant from the Seoul National University Bundang Hospital (09-2014-001).

\section{Availability of data and materials}

The data that support the findings of this study are available from the corresponding author upon reasonable request.

\section{Ethics approval and consent to participate}

Not applicable.

\section{Consent for publication}

Not applicable.

\section{Competing interests}

The authors declare that they have no competing interests.

Received: 16 January 2020 Accepted: 11 March 2020

Published online: 20 March 2020

\section{References}

1. Coburn SB, Bray F, Sherman ME, Trabert B. International patterns and trends in ovarian cancer incidence, overall and by histologic subtype. Int J Cancer. 2017;140:2451-60.

2. Newman DJ, Cragg GM, Snader KM. Natural products as sources of new drugs over the period 1981-2002. J Nat Prod. 2003;66:1022-37.

3. Rayan A, Raiyn J, Falah M. Nature is the best source of anticancer drugs: indexing natural products for their anticancer bioactivity. PLoS One. 2017;12: e0187925.

4. Jiang J, Hu C. Evodiamine: a novel anti-cancer alkaloid from Evodia rutaecarpa. Molecules. 2009;14:1852-9.

5. Kim D, Lee YH, Park SH, et al. Subchronic oral toxicity of evodia fruit powder in rats. J Ethnopharmacol. 2014;51:1072-8.

6. Lee $\mathrm{SH}$, Son JK, Jeong BS, et al. Progress in the studies on rutaecarpine. Molecules. 2008;13:272-300.

7. Wang QZ, Liang JY. Studies on the chemical constituents of Evodia rutaecarpa (Juss.) Benth. Yao Xue Xue Bao. 2004;39:605-8.
8. Ko HC, Wang YH, Liou KT, et al. Anti-inflammatory effects and mechanisms of the ethanol extract of Evodia rutaecarpa and its bioactive components on neutrophils and microglial cells. Eur J Pharmacol. 2007;555:211-7.

9. Shin YW, Bae EA, Cai XF, Lee JJ, Kim DH. In vitro and in vivo antiallergic effect of the fructus of Evodia rutaecarpa and its constituents. Biol Pharm Bull. 2007;30:197-9.

10. Jia S, Hu C. Pharmacological effects of rutaecarpine as a cardiovascular protective agent. Molecules. 2010;15:1873-81.

11. Park SY, Park C, Park SH, et al. Induction of apoptosis by ethanol extract of Evodia rutaecarpa in HeLa human cervical cancer cells via activation of AMP-activated protein kinase. Biosci Trends. 2017;10:467-76.

12. Park E, Lee MY, Seo CS, Jang JH, Kim YU, Shin HK. Ethanol extract of Evodia rutaecarpa attenuates cell growth through Caspase-dependent apoptosis in benign prostatic Hyperplasia-1 cells. Nutrients. 2018;10.

13. Ling $Y$, Hu $P$, Zhang $L$, et al. Identification and structural characterization of Acylgluconic acids, Flavonol glycosides, Limonoids and alkaloids from the fruits of Evodia Rutaecarpa by high performance liquid chromatography coupled to electrospray ionization and Quadrupole time-of-flight mass spectrometry. J Chromatogr Sci. 2016:54:1593-604.

14. Tang $X$, Huang $Z$, Chen $Y$, et al. Simultaneous determination of six bioactive compounds in Evodiae Fructus by high-performance liquid chromatography with diode array detection. J Chromatogr Sci. 2014;52: 149-56.

15. Yang $Y$, Wang $X$, Zhu Q, et al. Synthesis and pharmacological evaluation of novel limonin derivatives as anti-inflammatory and analgesic agents with high water solubility. Bioorg Med Chem Lett. 2014;24:1851-5.

16. Fujii A, Okuyama T, Wakame K, Okumura T, Ikeya Y, Nishizawa M. Identification of anti-inflammatory constituents in Phellodendri cortex and Coptidis Rhizoma by monitoring the suppression of nitric oxide production. J Nat Med. 2017:71:745-56.

17. Balestrieri E, Pizzimenti F, Ferlazzo A, et al. Antiviral activity of seed extract from Citrus bergamia towards human retroviruses. Bioorg Med Chem. 2011 19:2084-9.

18. Yao J, Liu J, Zhao W. By blocking hexokinase-2 phosphorylation, limonin suppresses tumor glycolysis and induces cell apoptosis in hepatocellular carcinoma. Onco Targets Ther. 2018;11:3793-803.

19. Chidambara Murthy KN, Jayaprakasha GK, Kumar V, Rathore KS, Patil BS. Citrus limonin and its glucoside inhibit colon adenocarcinoma cell proliferation through apoptosis. J Agric Food Chem. 2011;59:2314-23.

20. Kim J, Jayaprakasha GK, Patil BS. Limonoids and their anti-proliferative and antiaromatase properties in human breast cancer cells. Food Funct. 2013:4:258-65.

21. Rahman A, Siddiqui SA, Jakhar R, Kang SC. Growth inhibition of various human cancer cell lines by imperatorin and limonin from poncirus trifoliata rafin. Seeds Anticancer Agents Med Chem. 2014;15:236-41.

22. Patil JR, Chidambara Murthy KN, Jayaprakasha GK, Chetti MB, Patil BS, Bioactive compounds from Mexican lime ( Citrus aurantifolia) juice induce apoptosis in human pancreatic cells. J Agric Food Chem. 2009:57:10933-42.

23. Langeswaran K, Gowthamkumar S, Vijayaprakash S, Revathy R, Balasubramanian MP. Influence of limonin on Wnt signalling molecule in HepG2 cell lines. J Nat Sci Biol Med. 2013;4:126-33.

24. Barr MP, Gray SG, Hoffmann AC, et al. Generation and characterisation of cisplatin-resistant non-small cell lung cancer cell lines displaying a stem-like signature. PLoS One. 2013;8:e54193.

25. Crowley LC, Christensen ME, Waterhouse NJ. Measuring survival of adherent cells with the Colony-forming assay. Cold Spring Harb Protoc. 2016;8:721-5.

26. Laster SM, Mackenzie JM Jr. Bleb formation and F-actin distribution during mitosis and tumor necrosis factor-induced apoptosis. Microsc Res Tech. 1996:34:272-80

27. Xia Y, Shen S, Verma IM. NF-kappaB, an active player in human cancers. Cancer Immunol Res. 2014:2:823-30.

28. Ozaki T, Nakagawara A. Role of p53 in cell death and human cancers. Cancers (Basel). 2011;3:994-1013.

29. Liang SH, Clarke MF. Regulation of p53 localization. Eur J Biochem. 2001;268: 2779-83.

30. El-Deiry WS. The role of $\mathrm{p} 53$ in chemosensitivity and radiosensitivity. Oncogene. 2003;22:7486-95.

31. Sionov RV, Haupt Y. The cellular response to p53: the decision between life and death. Oncogene. 1999:18:6145-57.

32. Davis A, Tinker AV, Friedlander M. "Platinum resistant" ovarian cancer: what is it, who to treat and how to measure benefit? Gynecol Oncol. 2014;133: 624-31. 
33. Xia C, Bai X, Hou X, et al. Cryptotanshinone reverses Cisplatin resistance of human lung carcinoma A549 cells through Down-regulating Nrf2 pathway. Cell Physiol Biochem. 2015;37:816-24.

34. Zhong ZF, Tan W, Wang SP, Qiang WA, Wang YT. Anti-proliferative activity and cell cycle arrest induced by evodiamine on paclitaxel-sensitive and -resistant human ovarian cancer cells. Sci Rep. 2015;5:16415.

35. Chen TC, Chien CC, Wu MS, Chen YC. Evodiamine from Evodia rutaecarpa induces apoptosis via activation of JNK and PERK in human ovarian cancer cells. Phytomedicine. 2016;23:68-78.

36. Fauvet R, Dufournet C, Poncelet C, Uzan C, Hugol D, Darai E. Expression of pro-apoptotic (p53, p21, bax, bak and fas) and anti-apoptotic (bcl-2 and bcl$x$ ) proteins in serous versus mucinous borderline ovarian tumours. J Surg Oncol. 2005;92:337-43.

37. Sarrio D, Moreno-Bueno G, Sanchez-Estevez C, et al. Expression of cadherins and catenins correlates with distinct histologic types of ovarian carcinomas. Hum Pathol. 2006;37:1042-9.

38. Brun JL, Cortez A, Commo F, Uzan S, Rouzier R, Darai E. Serous and mucinous ovarian tumors express different profiles of MMP-2, $-7,-9$, MT1MMP, and TIMP-1 and -2. Int J Oncol. 2008;33:1239-46.

39. Cano A, Perez-Moreno MA, Rodrigo I, et al. The transcription factor snail controls epithelial-mesenchymal transitions by repressing E-cadherin expression. Nat Cell Biol. 2000;2:76-83.

40. Luca M, Huang S, Gershenwald JE, Singh RK, Reich R, Bar-Eli M. Expression of interleukin-8 by human melanoma cells up-regulates MMP-2 activity and increases tumor growth and metastasis. Am J Pathol. 1997;151:1105-13.

41. Cheng JC, Auersperg N, Leung PC. Inhibition of p53 represses E-cadherin expression by increasing DNA methyltransferase- 1 and promoter methylation in serous borderline ovarian tumor cells. Oncogene. 2011;30:3930-42.

42. Toschi E, Rota R, Antonini A, Melillo G, Capogrossi MC. Wild-type p53 gene transfer inhibits invasion and reduces matrix metalloproteinase-2 levels in p53-mutated human melanoma cells. J Invest Dermatol. 2000;114:1188-94.

43. Milner BJ, Allan LA, Eccles DM, et al. p53 mutation is a common genetic event in ovarian carcinoma. Cancer Res. 1993;53:2128-32.

44. Alexandre J, Ray-Coquard I, Selle F, et al. Mucinous advanced epithelial ovarian carcinoma: clinical presentation and sensitivity to platinumpaclitaxel-based chemotherapy, the GINECO experience. Ann Oncol. 2010; 21:2377-81.

\section{Publisher's Note}

Springer Nature remains neutral with regard to jurisdictional claims in published maps and institutional affiliations.

Ready to submit your research? Choose BMC and benefit from:

- fast, convenient online submission

- thorough peer review by experienced researchers in your field

- rapid publication on acceptance

- support for research data, including large and complex data types

- gold Open Access which fosters wider collaboration and increased citations

- maximum visibility for your research: over $100 \mathrm{M}$ website views per year

At $\mathrm{BMC}$, research is always in progress.

Learn more biomedcentral.com/submissions 